\title{
Severe hyperkalemia following ureteroileostomy: A case report and literature review
}

\author{
Majd Qasum ${ }^{1}$, Samuel N. Heyman ${ }^{2}$, Jasmin Khateeb ${ }^{1}$, Muhammad Abu-Arisha $^{1}$, Said Darawshi ${ }^{1}$, Gilad Amiel ${ }^{3}$, \\ Mogher Khamaisi*1,4 \\ ${ }^{1}$ Department of Internal Medicine, Rambam Health Care Campus, Haifa, Israel \\ ${ }^{2}$ Department of Medicine, Hadassah Hebrew University Hospitals, Jerusalem, Israel \\ ${ }^{3}$ Department of Urology, Rambam Health Care Campus, Haifa, Israel \\ ${ }^{4}$ Institute of Endocrinology, Diabetes \& Metabolism, Rambam Health Care Campus and Faculty of Medicine, Technion-Israel \\ Institute of Technology, Haifa, Israel
}

Received: December 26, 2017

DOI: $10.5430 /$ crim.v5n1p30
Accepted: January 16, $2018 \quad$ Online Published: January 25, 2018

URL: https://doi.org/10.5430/crim.v5n1p30

\begin{abstract}
Metabolic complications, including hyponatremia and metabolic acidosis have been reported following urinary diversion operations, occasionally together with hyper- or hypokalemia, depending on the bowel segment used. While Hypokalemia often accompanies ureterosigmoidostomy and may develop following ileal conduits, we report a rare case of recurrent life threatening hyperkalemia following this procedure, associated with hyponatremia and acidosis. Reviewing the English literature (1973 to 2016) we found 25 cases of hyperkalemia complicating ureteral diversion procedures, mostly after jejunal conduits. Only five cases of hyperkalemia were described after ileal conduit surgeries, including the current report. We discuss the nature of the metabolic and electrolyte disturbances following urinary diversion and debate possible reasons for the rare cases of hyperkalemia complicating ileal conduits.
\end{abstract}

Key Words: Metabolic acidosis, Hyponatremia, Ileal conduit, Hyperkalemia, Hypokalemia

\section{INTRODUCTION}

Ureteral diversion is a urologic procedure complementing bladder resection, in which the ureters are implanted into the sigmoid colon or into a conduit made of a segment of the small intestine. ${ }^{[1,2]}$ Implantation into the sigmoid has been largely abandoned due to severe metabolic problems and the increased risk of developing cancer. Diverse metabolic complications have been described following these procedures, usually with metabolic acidosis, hyponatremia and hyperor hypokalemia, depending on the bowel segment used. ${ }^{[3]}$ These complications evolve as the consequence of urine in the gut, and principally develop due to prolonged urine transit time, promoting ion and water transport or diffusion across the gut mucosa. While hypokalemia typically characterizes patients with ileal conduits, herein we present such a patient with the rare combination of metabolic acidosis, hyponatremia and repeated episodes of severe hyperkalemia.

\section{Case presentation}

A 70-year-old woman with advanced high-grade transitional cell carcinoma of the urinary bladder with bone and lung metastases underwent bladder resection with the formation of

\footnotetext{
*Correspondence: Mogher Khamaisi; Email: m_khamaisi@rambam.health.gov.il; Address: Department of Internal Medicine \& Institute of Endocrinology, Diabetes \& Metabolism Rambam Health Care Campus, POB 9602, Haifa 31096, Israel.
} 
an ileal conduit, with subsequent chemotherapy with carboplatin and gemcitabine. During the first two months following surgery she was hospitalized twice due to hyperkalemia and hyponatremia, (reaching $6.7 \mathrm{meq} / \mathrm{L}$ and $122 \mathrm{meq} / \mathrm{L}$, respectively) despite omitting treatment with enalapril. Noteworthy, biochemical and acid-base indices prior to bladder resection were all within normal limits. Four months later she presented with progressive shortness of breath and pleuritic chest pain. Her medications included insulin and omeprazole. On physical examination she appeared cachectic and dyspneic, with normal vital signs other than tachypnea and cyanosis, and without evidence of hypovolemia. Physical examination revealed findings compatible with massive Rt. pleural effusion, confirmed by chest X-rays. The ileal conduit was intact, draining straw colored urine.

Table 1. Laboratory data on admission

\begin{tabular}{|c|c|c|}
\hline \multirow{4}{*}{ CBC } & $\mathrm{Hb}$ & $11.7 \mathrm{~g} / \mathrm{dl}(12-15)$ \\
\hline & WBC & $11 \times 10^{3} /$ micro L (4-10.8) \\
\hline & Platelets & $610 \times 10^{3} /$ micro L $(130-400)$ \\
\hline & MCV & $87 \mathrm{fl}(80-98)$ \\
\hline \multirow{9}{*}{ Biochemistry } & $\mathrm{Na}$ & $124 \mathrm{mmol} / \mathrm{L}(133-145)$ \\
\hline & K & $7.5 \mathrm{mmol} / \mathrm{L}(3.4-5.3)$ \\
\hline & $\mathrm{Cl}$ & $93 \mathrm{mmol} / \mathrm{L}(95-110)$ \\
\hline & Glucose & $221 \mathrm{mg} / \mathrm{dl}$ (70-99) \\
\hline & BUN & 57 mg/dl (5-20) \\
\hline & Scr & $1.18 \mathrm{mg} / \mathrm{dl}(0.4-1.3)$ \\
\hline & $\mathrm{Ca}$ & $8.6 \mathrm{mg} / \mathrm{dl}(8.5-10.8)$ \\
\hline & $\mathrm{Mg}$ & $2.28 \mathrm{mEq} / \mathrm{L}(1.3-2.4)$ \\
\hline & IP & $2.2 \mathrm{mg} / \mathrm{dl}(2.5-4.5)$ \\
\hline \multirow{5}{*}{ Blood gases } & $\mathrm{pH}$ & $7.17(7.35-7.45)$ \\
\hline & $\mathrm{PCO}_{2}$ & $52 \mathrm{mmHg}(35-45)$ \\
\hline & $\mathrm{PO}_{2}$ & $22 \mathrm{mmHg}(75-90)$ \\
\hline & $\mathrm{HCO}_{3}$ & $16.9 \mathrm{mmHg}(22-26)$ \\
\hline & Lacate & $3.8 \mathrm{mmol} / \mathrm{L}(0-1.3)$ \\
\hline \multirow{4}{*}{ Urine chemistry } & $\mathrm{Na}$ & $30 \mathrm{mmol} / \mathrm{L}$ \\
\hline & K & $18 \mathrm{mmol} / \mathrm{L}$ \\
\hline & $\mathrm{pH}$ & $8(5-7.5)$ \\
\hline & Osmolarity & $383 \mathrm{mOsmol} / \mathrm{kg}(100-1,200)$ \\
\hline \multirow[b]{2}{*}{ Endocrinology } & Basal cortisol & 1,181 nmol/L (138-690) \\
\hline & $\begin{array}{l}\text { Stimulated } \\
\text { cortisol }\end{array}$ & $>1,350 \mathrm{nmol} / \mathrm{L}$ \\
\hline
\end{tabular}

Note. $\mathrm{CBC}=$ Complete blood count; $\mathrm{Hb}=$ Hemoglobin; $\mathrm{Scr}=$ Serum creatinine; BUN = Blood urea nitrogen; IP = Inorganic phosphate.

Laboratory evaluation, outlined in Table 1, disclosed normal anion-gap mixed metabolic and respiratory acidosis, associated with severe hyperkalemia $(7.5 \mathrm{mmol} / \mathrm{L})$ and hyponatremia. Electrocardiography showed tinted $\mathrm{T}$ waves on precordial leads compatible with hyperkalemia. The urine sediment was unremarkable and culture yielded mixed bacterial

Published by Sciedu Press growth. Abdominal sonography demonstrated hypoplastic kidneys (8.5 cm in size) without any lesions, hydronephrosis or stones. Basal and ACTH-stimulated cortisol levels ruled out Addison's disease (see Table 1). Tumor lysis and rhabdomyolysis were also excluded.

Hyperkalemia was successfully managed within $24 \mathrm{~h}$ with calcium gluconate, glucose-insulin infusion, inhalation of salbutamol and oral kayexalate. A chest tube, inserted into the Rt. pleural space drained 1,500 $\mathrm{ml}$ of malignant pleural effusion containing malignant cells of urinary bladder origin. Palliative treatment was administered and the patient died three days later with respiratory failure related to re-accumulation of pleural fluid.

\section{Discussion}

Our patient with metastatic carcinoma of the uroepithelium developed normal anion-gap metabolic acidosis (with concomitant respiratory acidosis), hyponatremia and severe hyperkalemia following bladder resection and the creation of an ileal conduit. While hyponatremia and hypokalemia are common metabolic complications of ileal conduit, hyperkalemia has rarely been encountered in these settings, and only four such patients have been reported so far in the English literature.

Hyponatremia and hyperchloremic (normal anion gap) metabolic acidosis, found in our patient are common complications in most surgical procedures using intestinal segments for urinary diversion. The former reflects uncontrolled water absorption by passive diffusion across the intestinal wall, preventing the excretion of diluted urine, in the same way hyponatremia develops in patients with uroperitoneum. ${ }^{[4]}$ The pathogenesis of hyperchloremic acidosis is more complex. It develops in some $80 \%$ of patients with ureterosigmoidostomy and is related to the luminal anion exchanger SLC26A3 that absorbs chloride and secretes bicarbonate across the sigmoid mucosa. Furthermore, breakdown of urea by intestinal bacteria with the consequent generation and absorption of ammonium also contributes to metabolic acidosis, as it undergoes transformation into urea with the generation of protons in the liver. Thus, acidosis is a major problem following ureterosigmoidostomy, ${ }^{[5]}$ but it is less prominent in patients with ileal neo-bladder, reflecting reduced contact of urine with the bowel mucosa. Indeed, in a large series of patients with ileal conduit, severe metabolic acidosis developed in only one percent of patients, although nearly one-half of them received alkalinizing treatment for mild acidosis. ${ }^{[6]}$ Interestingly, acidosis and hyponatremia were not encountered in patients with neo-bladders made of the ileo-cecal segments, as compared with traditional ileal conduits. ${ }^{[7]}$ The most common association of acidosis and urinary diversion procedures 
makes the surgical procedure the most likely cause. Yet, additional causes for normal anion gap acidosis should be considered, such as other disorders with gastrointestinal loss of bicarbonate or acquired urinary acidification defects. This later possibility is suggested by the high urinary $\mathrm{pH}$. However, we could not reveal a possible cause for acquired renal tubular acidosis in this case. Furthermore, urinary evaluation of samples obtained from an ileal pauch may be misleading: Likely, $\mathrm{pH}$ was determined in urine collected over a protracted period, containing numerous microbes, leading to a false reading of alkalosis due to urea breakdown to ammonia. Furthermore, pancreatic bicarbonate excretion could also increase urinary $\mathrm{pH}$ in this setup.

Regarding altered potassium balance, normally it is absorbed along the alimentary tract, with a net $84 \%$ fractional potassium absorption on the average in normal individuals. Potassium uptake takes place principally in the jejunum, with an estimated uptake of about $60 \mathrm{mEq} / \mathrm{day} \cdot{ }^{[8]}$ However, studies performed in patients with ileostomy, with or without partial ileal resection, indicate that some potassium uptake takes place along this intestinal segment as well. ${ }^{[9]}$ By contrast, net colonic handling of potassium is negative, presumably due to active potassium excretion, as well as loss by mucosal shedding and mucous excretion. ${ }^{[8]}$ In the presence of urine in contact with the gut mucosa these factors may lead to dramatic diverse changes, depending upon the gut segment involved. Indeed, ureterosigmoidostomy has often been associated with hypokalemia, ${ }^{[10]}$ which might be intensified by renal losses, mediated by protracted metabolic acidosis, ${ }^{[11]}$ with effective volume depletion and activated renin-angiotensin-aldosterone axis. ${ }^{[12]}$

By contrast, uretero-jejunostomy has been associated with hyperkalemia, presumably due to potassium reabsorption by the jejunal mucosa. ${ }^{[13]}$ Reviewing the literature published between 1973 and 2016 we found 25 cases of hyperkalemia complicating ureteral diversion procedures, 20 after jejunal and five, only (including our patient), after ileal conduit surgeries (see Table 2). Peak incidence was in patients aged 6070 years. Male gender was predominant, involving $82 \%$ of patients. The indication for surgery in most patients was malignancy, either of the bladder or the uterine cervix. A single study involved pediatric patients who underwent jejunal conduit surgery for neurogenic bladder and hydronephrosis. ${ }^{[14]}$ Hyperkalemia developed as early as two weeks after surgery, or presented later, by up to 2 months following surgery. Presenting symptoms were non-specific with nausea, vomiting and general weakness. One patient presented with quadriplegia, and another-with altered consciousness. In addition to hyperkalemia, hyponatremia was found in $70.8 \%$ of patients, (17 of 24 patients with available data), and 21/24 patients presented also with acute kidney injury, related perhaps to dehydration and fluid loss through the conduit (no data in one case).

Table 2. Reported case of hyperkalemia following ureteral diversion procedures

\begin{tabular}{|c|c|c|c|c|c|c|c|c|c|c|}
\hline Author & NOP & Age (Y) & $\begin{array}{l}\text { Gender } \\
\text { (M/F) }\end{array}$ & TOC & Indication for surgery & $\begin{array}{l}\text { Presentation } \\
\text { (W) }\end{array}$ & $\begin{array}{l}\mathrm{K} \\
(\mathrm{mEq} / \mathrm{L})\end{array}$ & $\begin{array}{l}\mathrm{Na} \\
(\mathrm{mmol} / \mathrm{L})\end{array}$ & pH & Treatment \\
\hline $\begin{array}{l}\text { Golimbu }^{[15]} \text {, } \\
1973\end{array}$ & 5 & $\begin{array}{l}56,53, \\
\text { ND }\end{array}$ & $(1,1)^{*}$ & Jejunal & Malignancy (1), ND (4) & $1.5-4$ & $5.7-7.2$ & 114-132 & ND & $\begin{array}{l}\text { Salt, } \\
\text { Bicarbonate }\end{array}$ \\
\hline Clark $^{[14]}, 1974$ & 9 & $1.5-69$ & $(8,1)$ & Jejunal & $\begin{array}{l}\text { Malignancy (4), } \\
\text { Hydronephrosis (3), } \\
\text { Neurogenic bladder (2) }\end{array}$ & $2-6$ & $5.5-8$ & 118-135 & ND & ND \\
\hline $\begin{array}{l}\text { Månsson }{ }^{[16]}, \\
1978\end{array}$ & 5 & $48-63$ & $(4,1)$ & Jejunal & Malignancy & $1.5-6$ & $5.2-8.2$ & $119-135$ & $7.24^{* *}$ & $\begin{array}{l}\text { Kayexalate, } \\
\text { Bicarbonate }\end{array}$ \\
\hline $\begin{array}{l}\text { Bonnheim }{ }^{[17]} \text {, } \\
1984\end{array}$ & 1 & 52 & $(1,0)$ & Jejunal & Malignancy & $<2$ & 7 & 130 & 7.4 & ND \\
\hline $\mathrm{Tak}^{[18]}, 1993$ & 1 & 67 & $(0,1)$ & Ileal & Malignancy & 2 & $4.8-6.4$ & $126-130$ & 7.4 & Kayexalate \\
\hline Koba $^{[19]}, 2004$ & 1 & 77 & $(1,0)$ & Ileal & ND & ND & 6.9 & 134 & 7.4 & ND \\
\hline $\begin{array}{l}\text { Eskandar }{ }^{[3]} \text {, } \\
2008\end{array}$ & 1 & 77 & $(1,0)$ & Ileal & ND & $<1$ & 5 & 133 & ND & $\begin{array}{l}\text { Low } \mathrm{K}^{+} \\
\text {enteral diet }\end{array}$ \\
\hline Hiew $^{[20]}, 2013$ & 1 & 80 & $(1,0)$ & Ileal & ND & $>16$ & 9.1 & ND & ND & ND \\
\hline $\begin{array}{l}\text { Qasum, } 2018 \\
\text { (Current report) }\end{array}$ & 1 & 70 & $(1,0)$ & Ileal & Malignancy & 10 & 7.5 & 124 & 7.17 & $\begin{array}{l}\text { Kayexalate, } \\
\text { Insulin, } \\
\text { Salbutamol }\end{array}$ \\
\hline
\end{tabular}

Note. YOP = Year of publication; NOP = Number of patients; TOC $=$ Type of conduit; $*=3$ patients with undetermined gender; $* *=$ Data available only for 1 patient; $\mathrm{Y}=$ Year; $\mathrm{W}=$ Weeks; $\mathrm{M}=$ Male; $\mathrm{F}=$ Female. $\mathrm{ND}=$ Not determined

The low incidence of hyperkalemia in patients with ileal conduits described in our literature review conceivably reflects the lower capacity to absorb potassium by the ileal mucosa, as compared with jejunal segments. ${ }^{[12]}$ The reason for its presence in our patient as well as in the four additional reported cases with ileal conduits is obscure. Surgical 
fault with the unintentional use of jejunal rather than ileal loops is unlikely in our patient, with the absence of previous abdominal surgery that could have led to anatomical distortion and mis-identification of the intestinal segments. Renal failure, increased dietary $\mathrm{K}^{+}$intake or intensified metabolic acidosis ${ }^{[6]}$ with concomitant respiratory acidosis might have also abruptly worsened hyperkalemia. However, that might not be the only explanation, especially since respiratory and renal compromise did not occur in the two prior admissions with hyperkalemia. Therefore, it is tempting to assume that in some patients ileal loops may have a better capacity of potassium uptake, comparable to the jejunal mucosa, especially when protractedly exposed to urinary potassium load, as happens with ileal pouch outflow stenosis.

In the absence of evolving renal failure, additional possible causes of true hyperkalemia, other than the consequence of the surgical procedure have been considered, such as enhanced endogenous input, addison's disease or hyporeninismhypoaldostronism. The first two options were ruled out in the absence of overt rhabdomyolysis, hemolysis or tumor lysis, and with the determination of high plasma cortisol. The unstable and terminal clinical condition and the need for intensive treatment of hyperkalemia precluded further evaluation of potassium homeostasis and urinary acidification and of the rennin-aldosterone axis. Estimated TTKG of about 2 suggests hypoaldostronism. Nevertheless, we could not

\section{REFERENCES}

[1] Mundy AR. Metabolic complications of urinary diversion. Lancet. 1999; 353: 1813-4. https://doi.org/10.1016/S0140-673 6(99) $90023-5$

[2] McDougal WS. Metabolic complications of urinary intestinal diversion. J Urol. 1992; 147(5): 1199-208. https ://doi .org/10.101 6/S0022-5347(17) 37517-1

[3] Eskandar N, Holley JL. Hyperkalaemia as a complication of ureteroileostomy: a case report and literature review. Nephrol Dial Transplant. 2008: 2081-3. PMid:18344237 https ://doi.org/10 $.1093 /$ ndt/gfn097

[4] Korem M, Ackerman Z, Sciaki-Tamir Y, et al. Post-partum acute kidney failure and hyponatremia - A clinical quiz. IMAJ. 2004, 6: 639-41. PMid:15473598

[5] Mills RD, Studer UE. Metabolic consequences of continent urinary diversion. J Urol. 1999; 161: 1057. https ://doi .org/10.1016/ S0022-5347(01) 61590-8

[6] Hautmann RE, de Petriconi R, Gottfried HW, et al. The ileal neobladder: complications and functional results in 363 patients after 11 years of follow up. J Urol. 1999; 161: 422. https ://doi .org/10 .1016/S0022-5347(01)61909-8

[7] Khafagy M, Shaheed FA, Moneim TA. Ileocaecal vs ileal neobladder after radical cystectomy in patients with bladder cancer: a comparative study. BJU Int. 2006; 97(4): 799-804. PMid:16536777 https://doi.org/10.1111/j.1464-410X.2006.05996.x

Published by Sciedu Press identify causes for recently acquired hypoaldostronism in the patient's clinical course. Furthermore, as with $\mathrm{pH}$ determination, TTKG assessment is likely useless in urine samples obtained from the ileal pouch, with potassium affected by transporters in the intestinal mucosa. Thus, without the determination of renin and aldosterone we cannot confirm that hypoaldostronism likely contributed to hyperkalemia. Yet, this case illustrates that despite the intuitive linking of acquired hyperkalemia and normal anion-gap acidosis with the surgical procedure, a careful consideration of other differential diagnoses should be carried out, with a critical clinical assessment, based on medical history, physical examination and complementing laboratory evaluation.

\section{Conclusion}

Metabolic abnormalities due to ileal/jejunal conduit surgery are common, chiefly hyponatremia, metabolic acidosis and hypokalemia. Hyperkalemia has been reported following urinary diversion using jejunal conduits, but may rarely develop following ileal conduit as well. Clinicians should be aware of these abnormalities and blood electrolytes and acid-base status should be closely monitored for several months following surgery for the early detection of potential life-threatening metabolic abnormalities.

\section{CONFLICTS OF INTEREST Disclosure}

The authors have declared no conflicts of interest.

[8] Agarwal R, Afzalpurkar R, Fordtran JS. Pathophysiology of potassium absorption and secretion by the human intestine. Gastroenterology. 1994; 107: 548. https://doi.org/10.1016/0016-5 085 (94) 90184-8

[9] Hill GL, Mair WSJ, Goligher JC. Cause and management of high volume output salt-depleting ileostomy. Br J Surg. 1975; 62: 720-6. PMid:1174816 https : //doi.org/10.1002/bjs. 1800620912

[10] Ozmen S, Danis R, Akin D, et al. Ureterosigmoidostomy [corrected]associated quadriparesis, non-traumatic rhabdomyolysis, and tetany in an adult. Int Urol Nephrol. 2008; 40(1): 245-7. PMid:18188675 https://doi.org/10.1007/s11255-007-9303-x

[11] Aronson PS, Giebisch G. Effects of pH on potassium: new explanations for old observations. J Am Soc Nephrol. 2011; 22: 1981 PMid:21980112 https : //doi.org/10.1681/ASN . 2011040414

[12] Wang T, Egbert AL Jr, Aronson PS, et al. Effect of metabolic acidosis on $\mathrm{NaCl}$ transport in the proximal tubule. Am J Physiol. 1998; 274: F1015. https://doi.org/10.1152/ajprenal.1998.274. 6.F1015

[13] Tanrikut C, McDougal WS. Acid-base and electrolyte disorders after urinary diversion. World J Urol. 2004; 22: 168. PMid:15290206 https ://doi.org/10.1007/s00345-004-0430-z

[14] Clark SS. Electrolyte disturbance associated with jejunal conduit. J Urol. 1974; 112(1): 42-7. https ://doi .org/10.1016/S0022-5 347 (17) 59638-X 
[15] Golimbu M, Morales P. Electrolyte disturbances in jejunal urinary diversion. Urology. 1973; 1(5): 432-8. https ://doi .org/10.101 6/0090-4295(73) 90374-9

[16] Månsson W, Lindstedt E. Electrolyte disturbances after jejunal conduit urinary diversion. Scand J Urol Nephrol. 1978; 12(1): 17-21. PMid:635483

[17] Bonnheim DC, Petrelli NJ, Sternberg A, et al. The pathophysiology of the jejunal conduit syndrome and its exacerbation by parenteral hyperalimentation. J Surg Oncol. 1984; 26(3): 172-5. PMid:6429449 https://doi.org/10.1002/jso.2930260307
[18] Tak PP, Diamant Z. Hyponatremia, hyperkalemia and hypercalcemia after ileal conduit diversion. Scand J Urol Nephrol. 1993; 27(2): 271-4. https://doi .org/10.3109/00365599309181264

[19] Koba K, Furuya R, Taira H, et al. A case report of complication liked jejunal conduit syndrome induced by reconstruction of ileal conduit. Nihon Hinyokika Gakkai Zasshi. 2004; 95(3): 630-3. https://doi.org/10.5980/jpnjurol1989.95.630

[20] Hiew K, Glendinning R, Parr N, et al. The twisted diversion: a paralyzing complication. J Surg Case Rep. 2013; 2013(1): rjs027. PMid:24963928 https://doi.org/10.1093/jscr/rjs027 